\title{
Presentation of adult Bland-White-Garland syndrome in a 32-year old female 败
}

\author{
Hakkı Şimşek ${ }^{\mathrm{a}}$, Mustaf Tuncer ${ }^{\mathrm{a}}$, Mehmet Yaman ${ }^{\mathrm{b}, *}$, Murat Çelik ${ }^{\mathrm{c}}$ \\ a Yuzuncu Yil University, Faculty of Medicine, Department of Cardiology, Van, Turkey \\ b Samsun Education and Research Hospital, Department of Cardiology, Samsun, Turkey \\ c Gulhane Military Medical Academy, Department of Cardiology, Ankara, Turkey
}

\section{A R T I C L E I N F O}

\section{Article history:}

Received 4 August 2015

Accepted 19 September 2015

Available online 28 September 2015

\section{Keywords:}

Bland-White-Garland syndrome

Coronary artery anomaly

Adult patients

\begin{abstract}
A B S T R A C T
Anomalous left coronary artery originating from the pulmonary artery (ALCAPA or Bland-White-Garland Syndrome) is a congenital coronary artery anomaly characterized by risk of death due to heart failure and sudden cardiac death. The probability of survival to adulthood is very poor in untreated patients. We present the case of an untreated 32-year old female patient with this congenital anomaly who has been asymptomatic till now even though she has had 3 uncomplicated pregnancies.

(c) 2015 The Society of Cardiovascular Academy. Production and hosting by Elsevier B.V. All rights reserved. This is an open access article under the CC BY-NC-ND license (http://creativecommons.org/licenses/by-nc-nd/4.0/).
\end{abstract}

\section{Introduction}

ALCAPA or Bland-White-Garland (BWG) Syndrome is very rare congenital anomaly affecting 1 in 300,000 live births, and accounts for $0.5 \%$ of cases of congenital heart disease. ${ }^{1}$ In this rare congenital condition, the left coronary artery originates from the pulmonary artery instead of the left sinus of Valsalva and perfusion of left ventricle is, therefore, dependent on the development of collaterals from the right coronary artery which originates from the right sinus of Valsalva. Approximately $80-90 \%$ of the afflicted infants die within 4 months of age due to heart failure and/or sudden cardiac death, ${ }^{2}$ and immediate surgical correction is recommended because of high risk of death. Nonetheless, survival to adulthood without any surgical correction is unusual and very few such cases have been reported to date. In this report, we present the case of a 32 year-old female with Bland-White-Garland Syndrome who has been asymptomatic until now, even though she has had 3 uncomplicated successful pregnancies.

Case

A 32 year-old female was admitted to our emergency department because of continuous chest pain for the last one hour. Her medical history was unremarkable and she was not taking any medication.

\footnotetext{
is Conflict of interest: The authors declare that they have no conflict of interest.

* Corresponding author at: Samsun Education and Research Hospital, Department of Cardiology, Ilkadım 55100, Samsun, Turkey. Tel.: +90 53347741 46; fax: +90 362216 8352.

E-mail addresses: hsimsek@gmail.com (H. Şimşek), tuncer@yahoo.com (M. Tuncer), dr.yaman@windowslive.com (M. Yaman), drcelik@hotmail.com (M. Çelik).

Peer review under responsibility of The Society of Cardiovascular Academy.
}

She previously had three uncomplicated pregnancies and deliveries (11 year-old, 7-year-old and 5-year-old healthy children) and did not experience any problem during the pregnancies. Nonetheless, she complained of increasing shortness of breath and atypical chest pain with exertion for the last two months. Physical examination was unremarkable. A 12-lead electrocardiograph (ECG), administered upon admission, showed a left anterior fascicular block and ST-segment depression in leads V3-V6. ECG changes are compatible with ischemia. There are no specify changes of ST/T waves in this condition Transthoracic echocardiography demonstrated absence of any valvular heart disease with intact left systolic function. There wasn't left ventricular hypertrophy. There were no abnormalities in complete blood count and standard biochemical tests on admission, and repeat troponin tests were negative. We next performed an elective coronary angiography. During coronary angiography, we were unable to visualize the left coronary artery (LCA) in the aorta (Fig. 1A). It was also noticed that the right coronary artery (RCA) was markedly dilated and tortuous, with retrograde supply to the LCA through numerous prominent collaterals. The contrast agent drained from the left main coronary artery into the pulmonary artery, thus permitting a diagnosis of anomalous LCA originating from the pulmonary artery (ALCAPA or BWG Syndrome) (Fig. 1B). Subsequently, in order to delineate coronary anatomy, multi-slice computed tomography (MSCT) coronary angiography was performed which showed that the RCA arose normally from the right sinus of Valsalva, but that the LCA arose from the main pulmonary artery (Fig. 2A-2B). Given the high risk of sudden cardiac death in these patients, even in adult patients with minor symptoms, we recommended immediate surgical correction. After transversal opening of the pulmonary artery, ostium of the left coronary artery was identified and closed with pericardial patch with 5-0 polypropylene running 


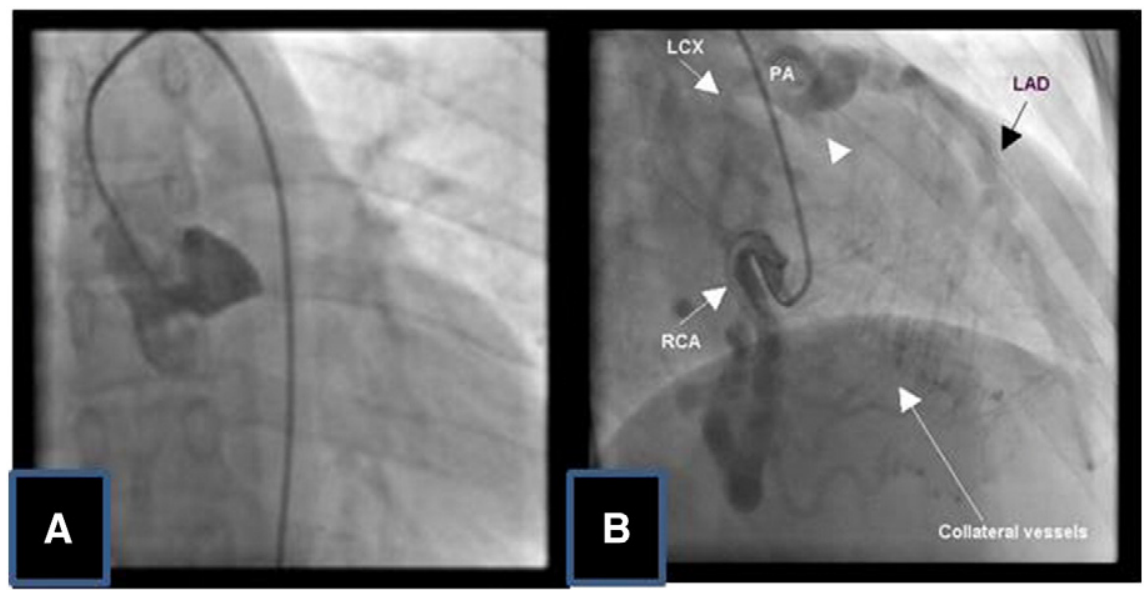

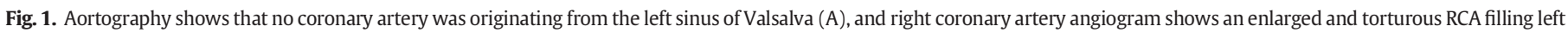

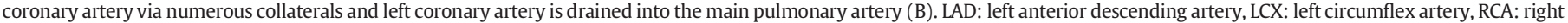
coronary artery, PA: pulmonary artery and arrowhead denotes the draining of contrast agent into the pulmonary artery.

suture (Ethicon, Somerville, NJ) and left coronary artery direct reimplantation of the LCA into the ascending aorta. TEE wasn't performed during the procedure. The clinical course after surgery was uneventful and the patient was doing well at the 6-month follow-up.

\section{Discussion}

The BWG syndrome is a very rare congenital anomaly and is usually fatal during the neonatal period. On the other hand, a recently published case report has shown that since many patients are asymptomatic until their death they remain undiagnosed. ${ }^{3}$ The clinical manifestation of this condition is gradual and depends on the alterations in pulmonary circulation that occur after birth. ${ }^{4}$ In the fetal period, systemic and pulmonary arterial pressures are equal, and from birth till about 2 months of age, because of the high resistance in pulmonary circulation, antegrade flow from the pulmonary artery to the LCA perfuses the left ventricle; thus sudden death is extremely rare in this age group. As pulmonary artery pressure gradually falls after 8 weeks of life, disruption of the left ventricular function begins because of low perfusion and low oxygen pressure. During this period, left ventricle perfusion or the extent of myocardial ischemia completely depends on the development of collateral circulation between the right and left coronary artery. If collateral flow is poor then the patient will die during the first year of life due to heart failure and/or sudden cardiac death. ${ }^{5}$ However, patients with well-established collaterals survive through the neonatal- and childhood period into adulthood without any symptoms. ${ }^{6,7}$ In our patient, no remarkable symptoms associated with heart failure appeared until the age of 32 years. Interestingly, she had three uncomplicated and successful pregnancies even though the pregnancies would have caused some degree of cardiac overload. We think that this patient remained asymptomatic until now due to an optimal balance between the dilated and tortuous RCA and LCA via well-established collaterals, and that the presenting symptoms are probably related to partial failure of this collateral circulation.

The diagnosis of BWG syndrome is made after a coronary angiography or a multi-slice $C T$, and three criteria must be met. These are: the LCA must not originate from the aorta, the LCA must originate from the pulmonary artery, and retrograde filling of the LCA from the RCA. ${ }^{7}$ Other salient findings that are indicative of ALCAPA include left axis deviation, abnormal Q-waves in leads I and a VL, poor R-wave progression and ST/T wave changes on ECG. ${ }^{6,7}$ An echocardiography may also uncover a previous anterolateral myocardial infarction, left ventricular hypertrophy, a dilated left ventricle with global hypokinesia, mitral insufficiency, and a reversal of flow from the LCA into the pulmonary artery, which constitutes a left-to-right shunt. The echocardiography can also reveal the presence of a turbulent diastolic flow within the
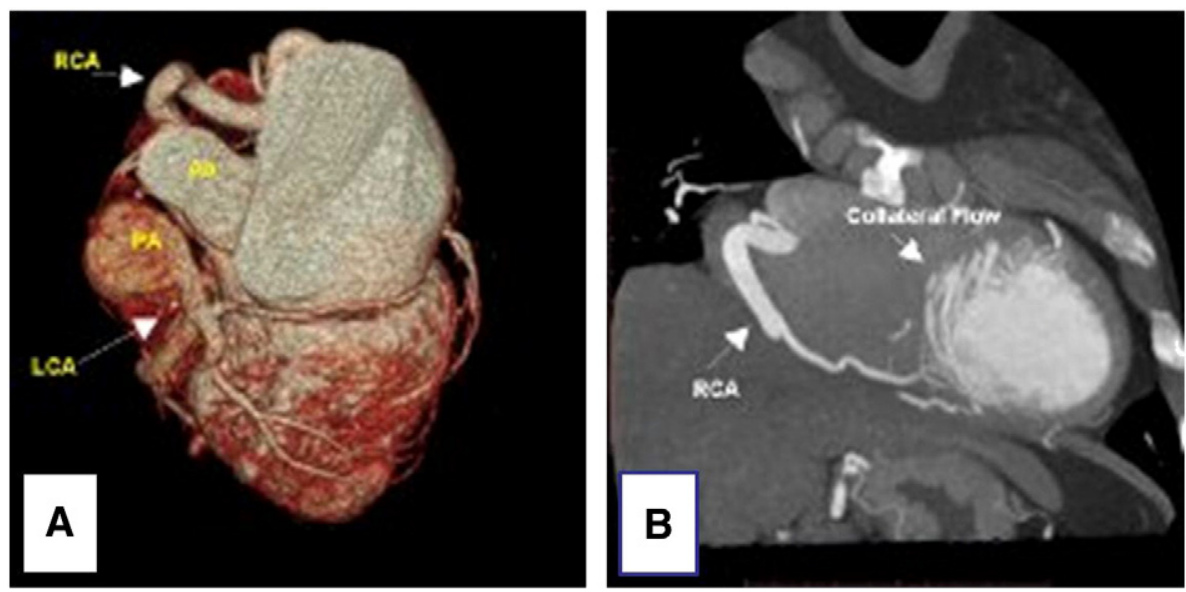

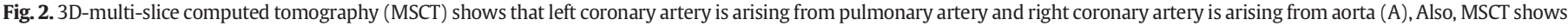

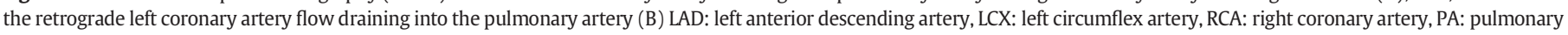
artery, Ao: aorta. 
interventricular septum as a result of inter-coronary collaterals, and a dilated and tortuous RCA in the parasternal short axis. ${ }^{8}$

Sudden cardiac death is the most common cause of death in adults with ALCAPA and this may very well be its first clinical presentation. The presence of scar tissue from previous myocardial infarctions and the coronary steal phenomenon caused by inadequate perfusion are potential causes of malignant ventricular arrhythmias in these patients. ${ }^{9}$ Therefore, immediate surgical correction after diagnosis is recommended in all patients, even in adult patients with only minor symptoms ${ }^{10}$ as it has been shown that left ventricle function improves after a successful re-establishment of coronary circulation. ${ }^{11}$

The BWG syndrome is a very rare congenital anomaly and individuals can remain asymptomatic well into adulthood and even during recurrent pregnancies, as seen in this case report. There are about 58 cases reported of survival to adulthood in literature. It is important to be aware of this syndrome because of the high risk of sudden cardiac death, even though patients may be asymptomatic. Immediate surgical correction after diagnosis is recommended.

\section{Comments}

Case characteristics

An untreated 32-year old female patient with this congenital anomaly who has been asymptomatic till now even though she has had 3 uncomplicated pregnancies.

\section{Clinical diagnosis}

Physical examination was unremarkable. A 12-lead electrocardiograph (ECG), administered upon admission, showed a left anterior fascicular block and ST-segment depression in leads V3-V6.

\section{Differential diagnosis}

Angına pectoris, Valvuler heart disease.

\section{Imaging diagnosis}

The patient underwent coronary angiography we were unable to visualize the left coronary artery (LCA) in the aorta It was also noticed that the right coronary artery (RCA) was markedly dilated and tortuous, with retrograde supply to the LCA through numerous prominent collaterals. The contrast agent drained from the left main coronary artery into the pulmonary artery, thus permitting a diagnosis of anomalous LCA originating from the pulmonary artery.

Multi-slice computed tomography (MSCT) coronary angiography was performed which showed that the RCA arose normally from the right sinus of Valsalva, but that the LCA arose from the main pulmonary artery.

\section{Treatment}

The patient underwent surgical correction with direct reimplantation of the LCA into the ascending aorta.

\section{Related reports}

It was rare in the literature that an untreated 32-year old female patient with this congenital anomaly who has been asymptomatic till now even though she has had 3 uncomplicated pregnancies.

\section{Experiences and lessons}

Despite Given the high risk of sudden cardiac death in these patients rare cases can be survival to adulthood.

\section{References}

1. Hasegawa H, Arimoto T, Iwayama T, et al. Images in cardiovascular medicine. Silent myocardial ischemia in adult Bland-White-Garland syndrome. Circ J 2010;74: 2239-2240 (PubMed PMID: 20668349).

2. Ercin E, Gamperli O, Kaufmann P, Eberli FR. Bland-White-Garland syndrome: extensive collaterals prevent ischaemia. Eur Heart J 2007;28:1672 (PubMed PMID: 17267454).

3. Wollenek G, Domanig E, Salzer-Muhar U, Havel M, Wimmer M, Wolner E. Anomalous origin of the left coronary artery: a review of surgical management in 13 patients. Cardiovasc Surg (Torino) 1993;34:399-405 (PubMed PMID:8282746).

4. Takimura CK, Nakamoto A, Hotta VT, Campos MF, Malamo M, Otsubo R. Anomalous origin of the left coronary artery from the pulmonary artery: report of an adult case. Arq Bras Cardiol. 2002 Mar;78(3):309-314 (PubMed PMID: 11967586).

5. Kurşaklıoglu H, İyisoy A, Çelik T, Günay C. Koroner Arter Anomalileri. In: Oto A Kurşaklığlu H, Iyisoy A, editors. Koroner Arter Anomalileri. Hacettepe Üniversitesi Hastaneleri Basımevi: Ankara; 2005. p. 16-91.

6. Barbetakis N, Efstathiou A, Efstathiou N, Papagiannopoulou P, Soulountsi V, Fessatidis I. A long-term survivor of Bland-White-Garland syndrome with systemic collateral supply: a case report and review of the literature. BMC Surg. 15;5:23. PubMed PMID: 16356181

7. Parale GP, Pawar SS. Adult type anomalous left coronary artery from pulmonary artery. J Assoc Physicians India 2006;54:397-399 (PubMed PMID: 16909738).

8. Barçın C, Baysan O, Barış B, et al. Late presentation of anomalous origin of the left coronary artery from the pulmonary artery (ALCAPA): How can clinicians diagnose? Gulhane Med J 2010;52:280-282.

9. Parizek P, Haman L, Harrer J, et al. Bland-White-Garland syndrome in adults: sudden cardiac death as a first symptom and long-term follow-up after successful resuscitation and surgery. Europace 2010;12(9):1338-1340 (PubMed PMID: 20348142).

10. Alexi-Meskishvili V, Berger F, Weng Y, Lange PE, Hetzer R, 309-15. Anomalous origin of the left coronary artery from the pulmonary artery in adults. 1995;10:309-315 (PubMed PMID: 7549188).

11. Arciniegas E, Farooki ZQ Hakimi M, Green EW. Management of anomalous left coronary artery from the pulmonary artery. Circulation 1980;62:I180-I189 (PubMed PMID: 6967375). 